\title{
Surgeons, valve repair in severely unbalanced atrioventricular septal defect, and the emperor's new clothes
}

\author{
David M. Overman, MD
}

\footnotetext{
From the Division of Cardiac Surgery, The Children's Heart Clinic; and the Division of Cardiovascular Surgery, Children's Hospitals and Clinics of Minnesota, Minneapolis, Minn.

Disclosures: Author has nothing to disclose with regard to commercial support.

Received for publication Aug 11, 2017; accepted for publication Aug 19, 2017; available ahead of print Sept 28, 2017.

Address for reprints: David M. Overman, MD, The Children's Heart Clinic, 2530 Chicago Ave S, Suite 500, Minneapolis, MN 55404 (E-mail: doverman@chc-pa.org).

J Thorac Cardiovasc Surg 2017;154:2028-9

$0022-5223 / \$ 36.00$

Copyright (c) 2017 by The American Association for Thoracic Surgery

http://dx.doi.org/10.1016/j.jtcvs.2017.08.050
}

[I]n short, no one would allow that he could not see these much-admired clothes, because in doing so, he would have declared himself either a simpleton or unfit for his office. Certainly, none of the emperor's various suits had ever made so great an impression as these invisible ones.

"But the emperor has nothing at all on!" said a little
child.

"Listen to the voice of innocence!" exclaimed his father; and what the child had said was whispered from one to another.

"But he hasn't got anything on!" the whole town cried out at last. The emperor shivered, for he suspected they were right. But he thought, "This procession has got to go on." So he walked more proudly then ever, as his noblemen held high the train that wasn't there at all.

— "The Emperor's New Clothes,"

Hans Christian Andersen

It is a universally acknowledged principle that preservation of native anatomy through successful valve repair is preferable to valve replacement in essentially all clinical settings. The crux of this principle hinges, however, on the word successful. Our literature is replete with single-institution observational reports of successful valve repairs of varying types applied to any number of anatomies. There is at least a subliminal, if not frankly overt, message that valve replacement is a form of surgical failure, and the frequency with which valve replacement proves necessary roughly correlates with a surgeon's technical prowess.

The report from Buratto and colleagues ${ }^{2}$ in this month's Journal challenges prevailing notions of the role of valve replacement in the management of patients with severely unbalanced atrioventricular septal defect (uAVSD). Perhaps ironically, the article's title invokes the aforementioned traditions of reports of improved outcomes in the setting the intervention.

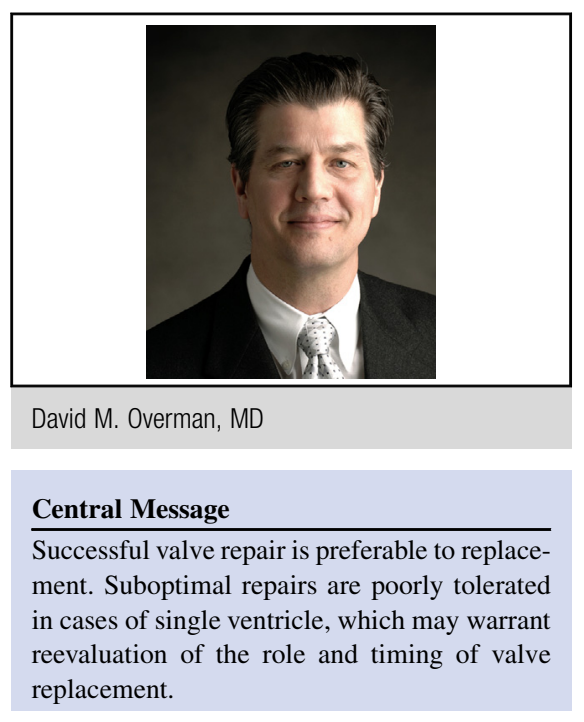

See Article page 2019.

of successful valve repair. It is of course true (with certain key caveats such as preserved ventricular function) that if a valve can be repaired with little or no residual insufficiency or stenosis, the patient will fare better than if such an intervention is not undertaken or is unachievable. What is a less obvious and probably underreported statistic is the number of "successful" repairs that carry residual valve dysfunction and in turn increase the ultimate impact of that disease burden. This is a particularly relevant notion in the setting of $\mathrm{UAVSD}$, because repair of a common atrioventricular (AV) valve is a far more challenging undertaking than repair of a tricuspid or mitral valve. (Indeed, the surgical creativity and ingenuity the infinite variety of common AV valve geometry demands make some technical reports on the subject resemble something akin to an National Football League playbook. ${ }^{3}$ ) What does the largest series of valve repair in single ventricle forms of uAVSD to date reveal?

- Among patients with uAVSD and single-ventricle anatomy, 1 in 3 required AV valve intervention.

- Of these patients, 1 in 5 did not survive the intervention.

- Nearly half of the cohort did not survive 10 years beyond

- When a patient was discharged with moderate or greater AV valve regurgitation, freedom from death or transplantation at 5 years was a dismal $33 \%$, and freedom from reintervention was $0 \%$. 
- Among the small number of patients in the series who underwent AV valve replacement, freedom from death or transplantation at 10 years was a favorable $75 \%$.

These are sobering data from a series purporting to describe improved outcomes in patients with successful valve repair. The report possesses the usual weaknesses of retrospective single-institution studies that span forty years. Among these, it is important to note the relative paucity of information about the role of ventricular dysfunction in both valve repair efficacy and overall clinical outcomes. Buratto and colleagues ${ }^{2}$ did not find a correlation between ventricular dysfunction and outcome, but the data are merely descriptive and were only available for 33 of the 44 patients in the series. The role of ventricular dysfunction in the outcome of these patients is well documented ${ }^{4}$ and powerful, and a more granular analysis of ventricular function in this cohort would have been helpful.

What is refreshing about this manuscript, however, is the objective and unapologetic analysis by Buratto and colleagues $^{2}$ of the results and their implications. The message from these data is clear: these patients are ill-served by strategies that equate success with tolerance of residual disease. Buratto and colleagues' suggestion ${ }^{2}$ that valve replacement may best be applied earlier in the clinical sequence of valve interventions represents a nontrivial departure from the current wisdom. And lest we become like the emperor's sycophants, our collective comfort with "successful" valve repairs in this patient population should perhaps lessen, and a fresh assessment of the role of traditional mechanical valve replacement be entertained.

\section{References}

1. Andersen HC, The Emperor's New Clothes. Available at: http://www.onlineliterature.com/hans_christian_andersen/967/. Accessed September 18, 2017.

2. Buratto E, Ye XT, Brizard CP, Brink J, d'Udekem Y, Konstantinov IE. Successful atrioventricular valve repair improves long-term outcomes in children with unbalanced atrioventricular septal defect. J Thorac Cardiovasc Surg. 2017; 154: 2019-27.

3. Ando M, Takahashi Y. Edge-to-edge repair of common atrioventricular of tricuspid valve in patients with functionally single ventricle. Ann Thorac Surg. 2007;84:1571-6; discussion 1576-7.

4. Honjo O, Atlin CR, Mertens L, Al-Radi OO, Redington AN, Caldarone CA, et al Atrioventricular valve repair in patients with functional single-ventricle physiology: impact of ventricular and valve function and morphology on survival and reintervention. J Thorac Cardiovasc Surg. 2011;142:326-35. 